\title{
The Development Trend of Electronic Commerce Based On Internet + Era
}

\author{
Wang Peng \\ Shaanxi Technical College of Finance \& Economics, Xianyang 712000 China
}

Keywords: Internet +; E-commerce; Development Trend

Abstract: Since the launch of the "Internet +" action development policy in China, it has greatly promoted the development of the industry and brought new development opportunities. With the emergence of e-commerce and Internet finance, both have a new development trend that suits them. "Internet $+"$ is the product of the development of information technology, and it also represents the information society.

\section{Introduction}

With the rise of Internet technology, Internet technology can be seen in all fields of the world, improving the quality of people's lives. At the same time, it has innovated the business development model, enabling e-commerce to rapidly transform and upgrade, expand the development platform, and promote the transformation and upgrading of the national industry. Based on the Internet + era, the integration of Internet platforms and traditional industries, increase the innovation of business activities, make the entire market full of life

\section{Internet + ERA background}

Looking back at the development history of the Internet for more than 20 years, China has gradually become a network power shocked at home and abroad. In the 2015, the number of Internet users in China has risen to 688 million, making it the largest number of Internet users in the world. In the process of Internet transformation and upgrading, contemporary enterprises and national governments have worked hard to promote the Internet. Yi Guan International chairman and chief executive Yu Yang first launched the "Internet +" idea. In March 2015, the government implemented the "Internet +" implementation program to bring together big data, mobile Internet, cloud computing and modern enterprises. The Internet has gradually evolved from ancillary tools to a new platform for industrial development.

\section{The status quo of e-commerce development under the Internet+ era}

With the advent of the millennium, combined with the statistical analysis of relevant data, China's economy continues to rise, and e-commerce is also facing a new development trend. Nowadays, the development trend of electronic commerce is maturing, and the state pays attention to it and integrates it into the national strategic policy, which improves the national economic 
benefit. The development of e-commerce has also improved its market share. The online retail market is an important factor driving China's economic development. Compared with the electronic commerce market structure, the core pillar of e-commerce in China is still the market between enterprises and enterprises because of the obvious difference of electronic commerce transaction amount of each enterprise. At this stage, the macroeconomic policy trend of the world's primary economic system is uncertain, and the emerging market flows of contemporary international capital are also uncertain, delaying the pace of international economic development, affected by domestic economic development trends and the environment, the accumulation of goods is a problem faced by many enterprises, and the consumer market is also in a state of saturation, and the market share between enterprises and enterprises is gradually declining. With the expansion of online shopping scale, so that the online retail market trading degree is relatively concentrated. For the market scale, the expansion of online shopping scale has made great contributions to the development of the retail market.

In terms of online shopping frequency, the consumer online shopping base is increasing, the market share is gradually increasing, the impulse consumption frequency of online shopping consumers has decreased, and rational consumption has begun. The rising speed from high speed to fast is the most common phenomenon of online shopping frequency. E-commerce has emerged in various regions, and the coastal areas in the southeast are concentrated, which makes the regional development uneven. Because the development of e-commerce relies too much on the level of regional infrastructure construction and regional informatization, the coastal region's economy is developing rapidly and on a large scale, and the central and western regions are developing slowly, resulting in uneven development.

\section{E-commerce development direction}

So far, many entrepreneurs, scholars and industry insiders have summarized many concepts according to their own values and the level of participation in e-commerce activities. In general, e-commerce is a kind of business activity with the help of microcomputer technology and network communication.

In the later stage of development, the development and innovation of microcomputer technology and network communication technology is very crucial. The importance of new media technology in the field of e-commerce applications will affect the later development of e-commerce. In view of the current situation, e-marketing has introduced a new model, which is a micro-business, which has low investment cost and high cost performance, and is a successful case of new media technology in the field of e-commerce applications. As of 2014, the micro-business shopping customers have more than 300 million people, the transaction amount of 150 billion RMB. It can be seen that the development of new media technology is very important.

At present, e-commerce is not a new sales model, and it is gradually being recognized and familiar. Such as Dangdang network, is a comprehensive online shopping center, which has a wide variety of items, including clothing, shoes, bags, pregnant babies and other items, and in 1999 added a book sales website. At the same time, the brands of other large e-commerce platforms are optimized according to the crowd. So far, the online and offline categories have become blurred. Evaluating the development trend of electronic commerce in the later stage with the development vision is a combination of the online and offline business of traditional enterprises and e-commerce enterprises. 


\section{Common problems in the development of e-commerce based on the Internet+ era}

\subsection{Transaction information is not secure}

E-commerce is gradually becoming familiar to people, providing convenience for people's lives and improving the quality of life. The information security issue is followed. Based on the Internet era, consumers and e-commerce are most concerned about the issue of e-commerce transaction security. With the rapid development of e-commerce industry, Internet financial security issues have attracted the attention and sustainability of consumers and e-commerce. In the process of e-commerce, financial information is done by means of the Internet, and to some extent, it is convenient for wrongdoers. According to the current development status of the Internet, it is still impossible to completely prevent the insecurity and instability caused by the network. Therefore, the transaction security issue has become the core content of e-commerce further discussion. The problem is still a technical problem, if consumer groups and e-commerce transactions, can ensure the integrity and security of information, improve network stability, and effectively block network hackers to steal transaction information and financial information. The transaction database and protection system can be completely saved, and if the above points are achieved, the security of e-commerce transactions can be fundamentally strengthened. Once the e-commerce transaction has caused security problems many times, it will cause the majority of consumer groups to question the e-commerce, and finally abandon this form of consumption, so that it loses its trust in the e-commerce industry, resulting in the loss of consumer groups, and It has a serious impact on the overall development of the Internet finance industry.

\subsection{The management system is not perfect}

In e-commerce financial transactions, not only security issues will arise, but also other problems, such as incomplete product information, low e-commerce reputation, untimely delivery of goods, and infringement issues, so we must further optimize the e-commerce industry. The society should increase the maintenance of consumer rights, pay attention to the details of the e-commerce industry, and improve the management and institutional system. Under the "Internet +" era, e-commerce industry has appeared a lot of novel business model. In an increasingly complex market environment, a complete legal and regulatory system and management system should be created. Although some e-commerce laws and regulations are not sound and are in the stage of improvement and adjustment, the behaviors such as point infringement and counterfeiting sales are still not well controlled, and there are mistakes and omissions in management. For example, the new professions that people know - online shopping brush sellers, online shoppers, and bad reviews from consumers, some warning events from merchants to consumers often occur. From these phenomena, we can clearly see the imperfect problems of the management system. At the same time, many consumers in the shopping process can not truly judge the quality and authenticity of the goods, resulting in incomplete product information, increasing the social pressure of e-commerce. Due to the gradual decline in the credibility of e-commerce, consumers are repelling Internet e-commerce. These phenomena have occurred repeatedly in the management of e-commerce industry.

\subsection{Low corporate reputation}

Corporate credibility is a prerequisite for accelerating enterprise development, and e-commerce is the same. With the rapid development of the market economy, individualism and self-interest have been reflected to some extent, leading to food safety problems repeatedly occurred, such as melamine, clenbuterol, etc., losing the trust of more and more consumer groups, fully reflecting the 
incompleteness of China's credit system and institution, and the company's self-consciousness is poor. Based on the "Internet +" era, e-commerce reputation issues are still the key issues that enterprises need to solve. First, because e-commerce companies do not have enough knowledge of legal knowledge, they cannot better implement the contract terms, trigger the triangular debt problem, bring damage to the corporate reputation image, make the enterprise unable to operate normally, and even worse, the enterprise will face bankruptcy. Second, in order to obtain high benefits, most e-commerce companies will mix fake and inferior products into good products, pay insufficient attention to product quality, and deceive consumer groups, which will have a serious impact on the development of e-commerce enterprises. Therefore, in order to better develop e-commerce, it is necessary to build a complete social credit system and create a good trading atmosphere so that more and more consumers can purchase with peace of mind.

\section{Ways to solve the problem of e-commerce development under the Internet+ era}

\subsection{Establish a sound legal security system}

Based on the Internet+ era, both Internet technology and network information technology have improved, and the technology has become more and more mature. It has a certain proportion in the construction of e-commerce, which is of great significance. In order to create a good e-commerce development atmosphere, e-commerce can be stepped into a good development track, strengthen the construction of the legal system, enable e-commerce development to have a complete set of laws and regulations system, access to the construction of e-commerce support, improve the institutional atmosphere. After an in-depth study of the history of e-commerce development, it can be seen that e-commerce is currently in the initial stage of development. There are a series of problems in this link, requiring scientific solutions to be developed, stabilizing the position of e-commerce in the market, creating a good environment for e-commerce construction, and strengthen the legal foundation. First, relevant departments conduct detailed research on the characteristics of e-commerce platforms, explore the legal issues and blank spots that appear in the development stage of electronic commerce, thereby filling and optimizing legal regulations and improving the legal security system. Second, the departments publicize laws and regulations, enhance the legal awareness of various enterprises, abandon the previous development ideas, strictly enforce the legal system, provide services that satisfy consumers, and optimize the e-commerce operating environment.

\subsection{Strengthen enterprise self-discipline}

Based on the Internet + era, the development of e-commerce faces some difficulties. The root of the problem is attributed to the poor self-discipline of the enterprise. It is too sloppy in the process of selecting a business strategy, and it is difficult to meet the current standard requirements for enterprise reform and development. Therefore, enterprises should continue to strengthen self-discipline thinking, consider issues in terms of long-term development of enterprises, choose development strategy goals, and transform business operations to further enhance their competitiveness. Strengthening the self-discipline of enterprises and changing the business strategy of enterprises can start from the following points: (1) Cost strategy. In the market economy, e-commerce has a strong influence, in terms of competitiveness is also very strong, in the final analysis is the cost and service issues. E-commerce companies must recognize their own advantages and continue to maintain, reduce operating costs through diversified means, invest more new technologies and advanced equipment, use low-cost strategic measures to control market development trends, so that the majority of consumers can enjoy more low price service. In any 
enterprise, the point that should be paid special attention is that enterprises are strictly forbidden to reduce prices to obtain consumers' love. Based on the principle of respecting market operation, the company reduces operating costs and seeks economic benefits for the consumer groups. (2) Differentiation strategy. E-commerce should establish innovative concepts, further study the characteristics and needs of market development, and at the same time master the reform and innovation of enterprises, build brands with the characteristics of this enterprise, and put the differentiation strategy in place. (3) Centralization strategy. E-commerce companies carefully plan market share, explore new customer groups, implement centralized strategies, expand enterprise benefits and business scope, and enable e-commerce to better adapt to the Internet platform.

\subsection{Improve the e-commerce operation system}

In-depth analysis of the current e-commerce operation situation, it is known that e-commerce currently has great difficulties in running infrastructure, logistics and technical personnel, which seriously restricts the creation of e-commerce operation system, and it is difficult to reflect the value and role of e-commerce. In the process of perfecting the e-commerce operation system, it is necessary to formulate solutions in light of relevant problems. (1) Increase the construction of information infrastructure. The key means to successfully carry out and maintain the smooth implementation of e-commerce activities is to build information infrastructure in various regions, especially in remote rural areas, broaden the information path, comprehensively cover the network, and further implement and expand the e-commerce platform. (2) Build a logistics system and increase supervision. With the smooth development of e-commerce activities, the value of logistics work matching it has emerged. In order to allow more consumers to buy products, it is necessary to establish a sound logistics system, so that product matching level has been improved. Therefore, it is necessary to quickly create a logistics system, integrate the three-level network system, business system, and logistics distribution system to complete the construction, improve the public distribution system, and build a complete logistics communication network. At the same time, consumers can check their own logistics information, follow up the logistics situation, and create a good logistics service environment for consumers. (3) Regularly organize technical personnel to participate in the training so that technical talents can actively participate in the network technology service and network security construction activities, and also cultivate more e-commerce personnel, so that they can show their own value in e-commerce, to promote the sustainable development of e-commerce enterprises.

\subsection{Improve transaction security}

The main problem faced by electronic commerce in the operation and development stage based on Internet + era is security, because e-commerce is in a relatively virtual environment, information security standards are very high, once the security of transaction information is affected, it will increase the economic pressure of consumers and enterprises, limit the development process of e-commerce. (1) The data information formed by e-commerce in the transaction process should be protected, so that the confidentiality and security of information can be improved to avoid revealing information about enterprises and consumers. All-round popularization and application security technologies, such as the use of symmetric and asymmetric encryption technologies in e-commerce business platforms to ensure the security of transaction information. (2) Innovate and improve the hacker defense system, regularly update the firewall, audit each software, fill the loopholes, and prevent virus attacks. Create multiple technologies to ensure the security of e-commerce platform operations. (3) Attach great importance to the work display of platform entities, improve the credibility of both parties to the transaction, and prevent unnecessary economic property loss caused 
by one party's mistakes. (4) Set up a group of high-quality, highly skilled e-commerce team, improve the overall quality of team personnel, to prevent internal personnel leaks.

\section{Conclusion}

In summary, with the rapid development of Internet technology, the scope of application of Internet technology has been broadened to a large extent. Strengthen the integration of business activities, promote the development of e-commerce platforms, and create opportunities for enterprise reform. Under the "Internet + " era, the development trend of e-commerce will become better and better, and promote the development of the socialist market economy.

\section{References}

[1] Xiong Wenjing. Analysis of E-commerce Security Issues in the Internet+ Era[J]. Information and computer, 2017(7):208-209.

[2] Gao Yanli, Liu Yong. Challenges and Choices of E-Commerce Development in the Age of "Internet + "[J]. People's Forum, 2016(5):109-111.

[3] Qin Chuhan. A Probe into the Development of E-commerce Based on the Background of "Internet +"[J]. Manager, 2017(03):256-257.

[4] Wang Mi. The Challenges and Strategic Countermeasures of E-Commerce Development under the "Internet + " Era

[J]. National circulation economy, 2016(3):18-19.

[5] Wang Zhu. Research on the Development Direction of E-commerce in the Age of "Internet + "[J]. Modern trade industry, 2016(8):199-200.

[6] Guo Weiguang, Zhang Chun. The development of e-commerce in the era of "Internet +"[J]. Digital world, 2017(6):113-114. 